\title{
Reflexão sobre as línguas nacionais no sistema de educação em Angola
}

Eduardo David Ndombele

Instituto Superior de Ciências da Educação do Uíge (Angola)

\section{Introdução}

Angola é um país situado na costa ocidental do continente Africano, com uma superfície de $1.246700 \mathrm{~km}^{2}$, dividido administrativamente por 18 províncias, com uma população estimada em 25.789.024 milhões de habitantes de acordo com os dados do Instituto Nacional de Estatística, referentes ao censo geral da população de 2014 (INE, 2016). O nome "Angola" tem a sua génese no título dos reis ambundu / kimbundu, "ngola" que existiu no antigo reino do Ndongo, entre Ambaca e Mphungo-Yandongo, as actuais províncias do kwanza Norte, Kwanza Sul, Bengo e Malange. Etimologicamente, o termo é do glosónimo kimbundu, vindo da palavra "ngola" que, ao ser traduzido para a Língua Portuguesa, significa "força".

Os contactos de Angola com o mundo ocidental começaram em 1482, com a chegada de Diogo Cão à Foz do Rio Congo. Antes da sua chegada, ainda não existia a nação angolana tal como a conhecemos hoje, mas, sim, eram diferentes etnias reunidas em reinos. Os primeiros contactos com os portugueses deram-se a partir do reino do Kongo, o primeiro Estado bantu a ser formado na costa ocidental de África, fundado entre 1200 e 1300 d. C. por Ntino Wene Wa Kongo (Nimi-a-Lukeni), com a capital em Mbanza Kongo. Era um Reino muito grande, limitado, ao Norte, pelo rio Ogoué, no Gabão; a sul pelo rio Kwanza; a Leste pelo rio Kwango, afluente do Zaire; a Oeste era banhado pelo oceano Atlântico (Nsiangengo et al, 2009 Apud Gomes, 2014 ).

Angola tem como língua oficial o português, mas possui várias línguas locais designadas por línguas nacionais ou regionais, distribuídas pelas seguintes Províncias: a) Cabinda: povos bakongo com o uso de língua kikongo variante (fiote); b) Zaire e Uíge: povos bakongo, língua Kikongo; c) Malanje, Kuanza-Norte, Bengo e Luanda: povos ambundu, língua kimbundu; d) Moxico, Lunda-Sul e Lunda-Norte: povos Tchokwe, Língua Cokwe; f) Bié, Huambo, 
Kwanza-sul, Benguela e Namíbe: povos Ovimbundu, língua umbundu; g) Huíla: povo Ovanyaneka-khumbi, língua olunyaneka; h) Kuando Kubango: o povo Ngangela; j) Cunene: povo Ovambo, língua oshikwanyama; 1) Namibe: Povos Ovahelelo, língua oshihelelo.

Além dos povos bantu, que são a maioria em Angola, esse território conta também com a presença das comunidades não bantu, os khoisan - grupo formado pelos hotentotes mais os vakankala, que são povos não negros, geralmente com uma estatura pequena, pele castanha clara, cabelos de tipo encaracolado e cujos olhos são do tipo oriental. Eles podem ser encontrados na faixa desértica do Namibe, na Serra da Chela, nas margens do Rio Cunene e na província do Kuando Kubango.

O Kikongo, durante muito tempo, gozou de um enorme prestígio no reino do Congo, não apenas nas actuais províncias de Cabinda, Uíge e Zaire, mas, sobretudo, nas trocas comerciais no Reino do Congo, que tinham como capital Mbanza Congo. 500 anos após a colonização em Angola, verificou-se uma profunda aversão a tudo quanto fosse línguas angolanas de origem africana. Essa aversão chegou a ponto de algumas reflexões saudosistas do processo de assimilação considerar os angolanos que não se expressam bem em Língua Portuguesa como se fossem estrangeiros dentro do seu próprio território. Agostinho Neto, o primeiro presidente de Angola, numa visão apocalíptica, já previa a nossa identidade cultural como um elemento inegociável ao afirmar que:

O uso exclusivo da Língua Portuguesa, como língua oficial, veicular e utilizável na nossa literatura, não resolve os nossos problemas. E tanto no ensino primário, como provavelmente no médio será preciso utilizar as nossas línguas. E dada a sua diversidade no País, mais tarde ou mais cedo devemos tender para a aglutinação de alguns dialectos, para facilitar o contacto (INL, 1979, p. 7).

Em "havemos de voltar", o poeta, médico e estadista angolano Agostinho Neto sublinha a importância da cultura africana. Assim, o autor deste poema faz um jogo rítmico que lembra uma canção, um hino. Neto demonstra, no poema, a vontade de voltar às origens, utilizando termos próprios do vocabulário dos povos bantu, como: marimba, kissange e mulemba. A esperança do poeta estava alicerçada na crença da libertação da cultura ante o sistema colonial, para a independência nacional. Abaixo transcrevemos o poema:

Às casas, às nossas lavras.

Às praias, aos nossos campos

Havemos de voltar.

Às nossas terras

vermelhas do café 


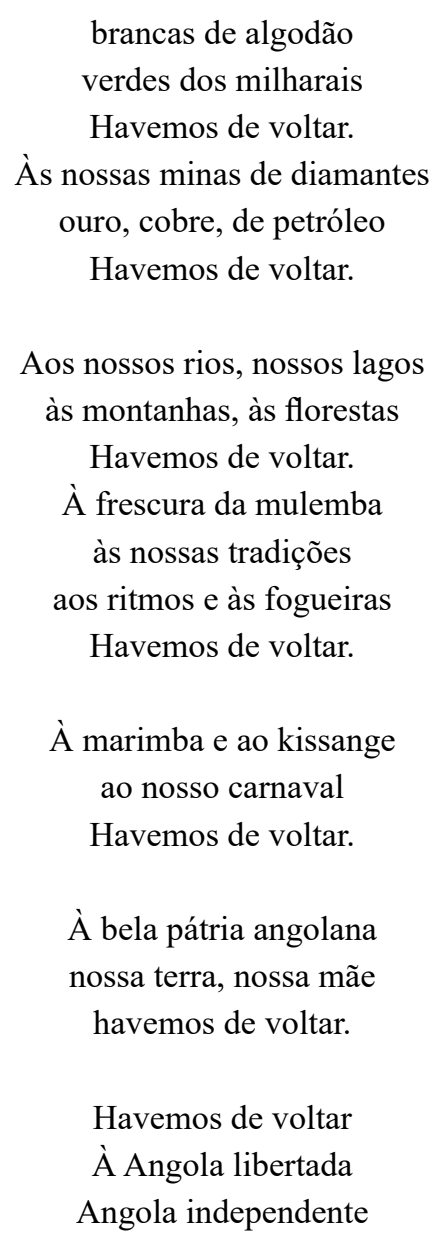

(FAAN, 2016)

Dois anos depois da independência (1977) e já com uma visão ampla, o presidente Neto alerta a jovem República sobre a reconversão linguística. Nesse contexto, dirigindo-se à União dos Escritores angolanos, afirmou: "Camaradas, neste momento já não é aceitável a ideia de fazer entrar na categoria de escritores apenas aqueles que manejam com perfeição a Língua Portuguesa" (Kukanda, 1988, p. 36). Esta atitude do primeiro Presidente de Angola revela a essência da política que pretendia colocar em marcha para o desenvolvimento a valorização das línguas nacionais, contrapondo, assim, as políticas de administração colonial que se consubstanciavam em dois pontos fundamentais: a) a portugalização total de Angola; e b) a destruição completa das línguas locais.

Deste modo, o desenvolvimento da nossa investigação procura responder às interrogações suscitadas em trabalho anterior sobre a tendência glotofágica da Língua Portuguesa no sub-sistema de ensino na República de Angola, no qual procedemos à avaliação da política educativa angolana, no que diz respeito à promoção das línguas bantu de origem angolana no sistema de educação, depois da aprovação da Lei $\mathrm{n}^{0} 13$ do sistema de educação em 2001 pela Assembleia Nacional de Angola. Assim sendo, afigura-se imprescindível continuar 
incidindo sobre a problemática do ensino de Línguas Nacionais no sistema de educação.

O presente estudo, portanto, constitui uma resposta sistematizada à seguinte pergunta: Será que atual reforma educativa conseguiu resolver a problemática do ensino de línguas nacionais em Angola? Na base da questão formulada e dada a sua importância, propusemo-nos a alcançar os seguintes objetivos: a) demonstrar a importância das línguas nacionais no processo de ensino e de aprendizagem, uma vez que a língua de um povo constitui um dos pilares culturais de uma comunidade e de um Estado e; b) contribuir com algumas propostas para um ensino bilíngue em Angola. Com a contribuição de estudos já existentes, acreditamos que o presente capítulo tornar-se-á uma mais-valia, para uma reflexão sobre as línguas nacionais no sistema educativo em Angola.

Para além da introdução, esse capítulo é composto por cinco secções, assim descritas: Na primeira secção, fazemos uma breve caracterização das línguas no sistema de ensino em Angola. Na segunda, fazemos uma apresentação da variedade do português em alguns municípios da Província do Uíge, que dista cerca de $360 \mathrm{~km}$ de Luanda, capital de Angola. Na terceira secção, por sua vez, apresentamos a situação do multilinguismo em Angola, na qual destacamos o lingala, uma língua que não faz parte do conjunto das línguas nacionais de Angola, cujo número de falantes cresceu vertiginosamente em todo território angolano ao ponto de muitos estudiosos de línguas considerar o lingala como a segunda língua mais falada em Angola depois do português. Na quarta secção, fazemos uma breve incursão sobre as políticas linguísticas na visão de Calvet (2002) e Oliveira (2003; 2005). Finalmente, na quinta secção, apresentamos uma proposta a fim de despertar os acadêmicos sobre a necessidade de se implementar o ensino bilíngue em Angola, fundamentalmente nas zonas rurais onde muitas crianças entram à escola sem o conhecimento da LP.

\section{Caracterização das línguas angolanas no sistema de ensino}

O Sistema educativo de Angola teve como ponto de partida o sistema educativo colonial que influenciou na criação de políticas educativas do governo angolano desde a primeira reforma após a independência (1977) e da segunda reforma promulgada através da Lei $\mathrm{n}^{\circ} 13$ de 2001. No período colonial, Norton de Matos (Alto comissário de Portugal em Angola), defendeu a instrução em Angola como meio de civilização dos angolanos, utilizando para o efeito a Língua Portuguesa (LP) como principal instrumento desta civilização, através de ações de um imperialismo linguístico inédito na administração francesa, inglesa e alemã, chegando ao ponto de proibir o uso de qualquer língua de origem africana em Angola através de decretos 
que codificavam o angolano como o dono da terra ${ }^{1}$, tal como se pode ler nestes artigos publicados em 1921:

Artigo $1^{\text {o: }}$ ponto 3: "É obrigatório, em qualquer missão, o ensino da Língua Portuguesa"; ponto 4: "É vedado o ensino de qualquer língua estrangeira";

Artigo 2o: "Não é permitido ensinar, nas escolas de missões, línguas indígenas";

Artigo $3^{\circ}$ : "O uso de língua indígena só é permitido em linguagem falada na catequese e, como auxiliar, no período do ensino elementar de Língua Portuguesa."

O sistema colonial defendeu, de igual modo, a separação da educação ministrada aos africanos daquela ministrada aos portugueses. Para o indígena, a instrução literária limitava-se somente a falar, ler e escrever o português, as quatro operações aritméticas e o conhecimento da moeda corrente de Angola. Tratava-se de simples palestras sobre higiene das pessoas e das habitações, contra os vícios e práticas nocivas, usos e costumes nefastos das vidas dos indígenas sobre a história de Portugal e os benefícios da civilização portuguesa.

Essa política educacional teve continuidade nos anos que se seguiram à presença de Norton de Matos em Angola. Acentuaram-se e generalizaram-se os discursos sobre a superioridade da raça europeia, com destaque para Armindo Monteiro, ministro das Colônias entre 1931-1935, que justificava a presença de portugueses em Angola com a missão civilizadora de tratar e cuidar do negro. Os africanos transformaram-se, assim, em súbditos, e não em cidadãos, pois, tendo muitos deveres, usufruíam de poucos ou nenhum direito. Em consequência dessa política educativa seletiva, Angola chegou à independência com uma taxa de analfabetismo na ordem dos $85 \%$, uma das mais elevadas do mundo (Liberato, 2014). Aliás, na senda do artigo $3^{\circ}$ supracitado, o então Comissário de Portugal em Angola (Norton de Matos) advogava que as línguas indígenas de Angola, o Kibundu, o Umbundu e tantas outras, apenas lhe interessavam como elemento de estudo da linguística, da evolução social de comunidades humanas e do desenvolvimento mental da humanidade. O mesmo julgava que essas línguas se obliterassem e desaparecessem de todos, pois que ele as considerava como línguas de cão.

Entretanto, a valorização das línguas angolanas é concebida como um potente factor da desalienação, de libertação ideológica através de uma renovada confiança em nós próprios, que o colonialismo nos tinha retirado desde as primeiras classes. Assim, elas, ao se constituírem como matérias de instrução, devem também

1. A respeito disso, Eduardo Mondlane, em 1969, dizia: "Tem sido costume entre os Europeus e os americanos conceber todo pensamento humano como proveniente do espírito ocidental. Em particular à África nunca foi atribuída qualquer contribuição para o desenvolvimento humano; sempre foi olhada com um mundo fechado e completamente atrasado, trazido para a corrente do desenvolvimento em resultado da invasão europeia." 
constituir disciplinas autônomas e veículos de transmissão de conhecimentos e técnicas. Segundo Santos (2006),

\begin{abstract}
devemos ter a coragem de assumir que a língua portuguesa, adaptada deste a nossa independência como língua oficial do país e que já é hoje a língua materna de mais de um terço dos cidadãos angolanos, se afirma tendencialmente como uma língua de dimensão nacional em Angola. Isso não significa de maneira nenhum, bem pelo contrário, que nós devemos alhear da preservação e constante valorização das diferentes línguas africanas de Angola, até aqui designadas "línguas nacionais", talvez indevidamente, pois quase nunca ultrapassam o âmbito regional e muitas vezes se estendem para além das nossas fronteiras (Santos, 2006, p.23).
\end{abstract}

No caso de Angola, estas recomendações, ao serem analisadas a partir da constituição da Quarta República com um olhar atento à Lei de Bases do sistema de educação, mostram um contraste nessa matéria. A seguir, citamos: "a língua oficial de Angola é o português", (Angola, 2010). E o texto prossegue: "O Estado valoriza e promove o estudo, o ensino e a utilização das demais línguas de Angola, bem como das principais línguas de comunicação internacional", (Idem, Art. $19^{\circ}$, ponto 2). "O Ensino nas escolas é ministrado em língua portuguesa" (Lei de bases do sistema de educação ponto 1 , Art $9^{\circ}$ de 2001).

O Estado promove e assegura as condições humanas, científico-técnicas, materiais e financeiras para a expansão e a generalização da utilização e do ensino das línguas nacionais (Lei de Bases do sistema de educação, Art. $9^{\circ}$, ponto 2), sem prejuízo do ${ }^{\circ} 1$ do presente Art., particularmente no subsistema de educação de adultos. Destacamos: "O ensino pode ser ministrado nas línguas nacionais" (Lei de Bases do sistema de educação, Art. $9^{\circ}$ ponto 3, 2001, grifo nosso).

Analisando profundamente os pressupostos constitucionais e legislativos acima fraseados, dos pontos 1 e 2 da atual Constituição da República e nos pontos 1, 2 e 3 da atual "Lei de Bases de Educação", ao nosso entender, existem entre estes pontos um pequeno contraste que torna, por vezes, necessários ajustes. Uma vez que a Lei de Bases do sistema de educação veda o ensino de línguas nacionais em alguns subsistemas, ao confirmar que elas podem ser ensinadas no subsistema de ensino de adulto - a partir de uma suposição "pode ser" -, essas expressões conferem apenas o poder a essas línguas no subsistema de ensino de adulto, desenquadrando-se dos outros pontos. Contudo, salientamos que as línguas de Angola desempenham um valor muito importante nas comunidades, porque (a) elas servem como o meio de comunicação por excelência entre falantes do mesmo código linguístico, (b) ajudam a salvaguardar as identidades culturais, costumes, valores éticos, tradições transmitidas de geração a geração e (c) o seu uso promove um melhor ajustamento entre o meio familiar e o escolar. 
A LP é a língua com o estatuto privilegiado como língua oficial em Angola. Ela é, pois, a única língua utilizada na administração, na imprensa e na escola, como sucedia no período colonial. Desta forma, ela cumpre uma das funções mais importantes: a da aprendizagem no sistema educativo. Essa constatação, portanto, deveria abranger o ensino em todos seus níveis.

O português de Angola apresenta variedades ou modificações em vários aspectos, em função de seus usuários/falantes. Essas características, muitas vezes, são verificadas em nível de pronúncia (fonologia), que nos pode identificar a região de origem do falante, como exemplo: em alguns pontos do país, como em Luanda, substitui-se o fonema $/ 1 /$ por $/ \mathrm{r} /$, como é o caso das palavras balde e almoço que são pronunciadas barde e armoço. Em algumas regiões como no Uíge e Zaire, eliminam-se o /r/ nas palavras com duplo /r/ ou acrescentam esta letra nas palavras em que não se necessita da duplicação da mesma letra, como nos exemplos: CARRO=CARO (Jacinto, 2016). Neste contexto, refere-nos Camara apud Rodrigues (2012, p.34):

\footnotetext{
Que são frequentes, numa língua, as variações fonológicas, sintácticas, morfológicas e lexicais e não há norma que consiga sobrepor-se e controlar a aquisição espontânea e os usos individuais da língua. As mudanças começam por ser individuais. Logo que não haja estigmatização ou rejeição colectiva, elas cristalizam-se e passam a integrar a norma da língua, como podemos constatar em algum léxico angolano. Machimbombo, quitandeira, fuba, comuna, sanzala, seculo, capim, ginguba, gindungo, loengos, etc. Por outro lado, há o uso particular de verbos como no caso ter (= haver), exemplo:) No mar tem muitos peixes (...). Existe também a redução de expressões e /ou sintagmas como no exemplo: (...) O leite é um bom alimento porque é dele (a partir dele) que podemos fabricar a manteiga (...). Ao nível da morfo-sintaxe o falante angolano tem dificuldade em fazer o acordo do verbo com o sujeito em pessoa e número.
}

Quando duas línguas entram em contacto, "verifica-se uma alteração a nível do léxico e da sintaxe e sobretudo na estruturação fonológica. Na sintaxe, é obrigatório que a ordem seja directa, como na Língua Portuguesa: Sujeito, Verbo e Complemento. A Língua Portuguesa domina as línguas locais que com ela preexistem, deixando marcas nelas" (Quivuna, 2014, p. 87).

\section{Variedade do português em alguns municípios do Uíge}

Uíge é uma das dezoito (18) províncias de Angola, situada ao Norte do país, com uma superfície estimada de $64.022 \mathrm{~km} 2$. Povo genuinamente bantu, que desde os tempos remotos tem respeitado a cultura dos ancestrais. Administrativamente, a província do Uíge é subdivida em dezesseis (16) municípios, nomeadamente: Alto Cauale, Ambuíla, Bembe, Buengas, Bungo, Damba, Kimbele, Kitexe, Macocola, Maquela do Zombo, Mucaba, Negage, Puri, Sanza Pombo, Songo e Uíge a capital da Província. 
Antes da chegada dos navegadores portugueses à foz do rio Kongo (Zaire), a 13 de Março de 1482, Uíge já existia, pois circunscrevia-se dentro do reino do Kongo, organizadamente como um estado independente da sua administração como outros reinos, tendo uma língua bantu, o Kikongo, e a cultura Bakongo. Não se sabe a data exata da fundação da pitoresca cidade do Uíge. Sabe-se, porém, que foi o enviado Alferes Tomás do Bembe ao Candombe Velho, onde se encontrava o soba Nbunzu, a quem entregou a mensagem enviada pelo comandante, cujo teor dizia respeito à criação da Sede distrital do Uíge. Isso permitiu ao governo de Luanda exarar um decreto-lei de 1 de Julho de 1917 da promoção do conselho do Uíge a cidade. Essa data, desde então, é reconhecida como a de sua fundação, tornando-se o dia festivo nesta cidade (Mudiambo, 2014).

Geograficamente, o município do Uíge é a sede da capital da província, tendo uma superfície de $3600 \mathrm{~km}^{2}$, limitada a Norte com os municípios do Mucaba e Bungo, a Sul com o município do Quitexe, a Leste o município de Negage e a Oeste os municípios de Ambuila e Songo. Essa província controla, assim, 21 Regedorias, 84 aldeias e 12 Quarteirões. Demograficamente, o município confere no seu total um número de 519.196 habitantes, segundo os dados definitivos do Censo Geral da população e Habitação realizado em 2014 (INE, 2016). Referindo-nos à questão etnolinguística, o município é marcado por várias línguas, nomeadamente três, em destaque, a LP, o Lingala e o Kikongo. Essas línguas interagem cotidianamente entre elas, ocorrendo, assim, o processo de empréstimo de certas unidades lexicais de uma língua para outra, fortalecendo o léxico de cada língua.

Dange Quitexe é um dos municípios da província do Uíge localizado ao Sul, com uma extensão de $38.702 \mathrm{~km}^{2}$, limitando-se com o município de Negage ao Nordeste, ao Leste o município de Ambaca e Bolongongo da província do Kuanza Norte, na parte Sul os municípios da província do Bengo (Nambuangongo e Dembos) e ao Sudoeste com o município do Ambuíla. Administrativamente, confere 3 comunas: a comuna da Aldeia Viçosa, Vista Alegre e a do Cambamba; 17 regedorias; 75 aldeias das quais 25 na sede municipal, 20 na comuna da Aldeia Viçosa, 22 na Vista Alegre e 8 em Cambamba. De acordo os dados do Censo Populacional, o município é estimado em 32.818 habitantes. Quanto ao âmbito linguístico demarca a LP, Kikongo e o Kimbundu.

O Português falado pelos habitantes do município do Uíge e pelos de Dange Quitexe, apresenta em seu nível fônico diferenças ou mudanças que, às vezes, permitem distinguir a região de origem. Estas mudanças são provocadas por diversos fatores: geográficos, emigratórios, acadêmicos etc. Esta língua veiculada nos dois municípios apresenta algumas diferenciações em que, em primeiro molde, temos a mudança que diz respeito ao espaço geográfico, isto apresenta 
as variações diatópicas; variações diastráticas; no terceiro tem as variações diafásicas.

Para Jacinto (2016), o português falado nas regiões do Uíge e do Quitexe tem sofrido algumas alterações, na medida em que as mesmas cidades recebem os contactos de língua como o Kimbundu e o Kikongo com o português - isto realmente afeta a pronúncia dos falantes destas comunidades. É óbvio que essas mudanças fazem com que o português falado nos dois municípios funcione de uma forma diferente no âmbito da pronúncia. As consequências desta variação linguística afetam, majoritariamente, o plano fonético, pois que essas alterações encontradas na pronúncia podem também atingir a ortografia destas palavras, tal como ocorre com a substituição de um grafema por outro: aroz, parra, armufada.

$\mathrm{O}$ alfabeto do Kikongo difere do português, pois algumas letras não existem nele (c, h, j, g, q, r, x). O alfabeto da língua Kikongo não dispõe do mesmo número de letras que o português, todavia a sua ortografia não difere muito da do português. Quiala (2013) esclarece que a língua kikongo "é uma língua de prefixos, de prefixação como o são quase todas as línguas bantu, obtendo-se o plural dos nomes e a concordância das frases com prefixos e não com sufixos, como é no caso das línguas europeias, que são de sufixação" (Quiala, 2013, p.24).

Os falantes de kikongo (como língua materna) não alfabetizados ou sem nenhum conhecimento da gramática da LP tendem a transferir as regras do kikongo ao português, o que causa variação. Assim, escrevem palavras portuguesas da maneira que são expressas, como ocorre em casa (caza), exemplo (ezemplu), vem (vei), hora (orra). Ou seja, com a falta do $\mathrm{H}$ no alfabeto kikongo, suprime-se o $\mathrm{H}$ (ora) e, por se ter uma pronúncia forte, duplicam o R (orra). Outra questão que se tem notado é a pronúncia da letra $\mathrm{R}$, em que outros falantes transportam este fenômeno até à grafia: parar (parrar), arroz (aroz), carro (caro), paragem (parragem), terra (tera); ainda constata-se a questão da concordância nominal em certas palavras ou a substituição de pronomes e determinantes artigos, isto é, no discurso oral: aquela miúdo, a Joaquim, aquele mulher, este casa.

Os prefixos nominais estão divididos em classes. A palavra muntu (homem, pessoa), por exemplo, pertence à $1^{\mathrm{a}}$ classe e à $2^{\mathrm{a}}$ classe um-ba-a, wa que designam o prefixo do singular e do plural, respectivamente e que se antepõem ao radical ntu, ficando muntu $=\mathbf{m u}+\mathbf{n t u}$, no singular antu $=\mathbf{a}+\mathbf{n t u}, \mathbf{b a}+\mathbf{n t u}$ ou wantu= wa + ntu, no plural. Eis alguns exemplos: "Muntu ---- antu, bantu, wantu--- pessoa/pessoas" (Quiala, 2013, p. 24).

Outro caso que se verifica é a falta de acentuação das palavras em Kikongo, alguns acarretam ao Português: máquina (maquina), José (Jose), fábrica (fabrica). Isto é o resultado da norma da Língua Kikongo, de acordo com a qual as palavras 
não se acentuam graficamente, sem ter em conta que em Português este fator é essencial, porque sem ele a palavra ou a frase perde o sentido (Jacinto, 2016). O Kimbundu, na província de Uíge, é falado nos municípios de Dange-Quitexe, Negage e Kangola. Como já afirmamos, essa província é majoritariamente habitada pelos Bakongo, mas os Kimbundo também têm uma sedentarização na província devido aos limites das vizinhas províncias de Malanje, onde terá pertencido o Município de Kangola na antiga administração colonial ou por pertencer ao reino do Ndongo entre Ambaca e Mphu-yandongo e as províncias do Bengo e Kwanza Norte nas fronteiras de Negage e Quitexe respectivamente. Este grupo etnolinguístico constitui o grupo minoritário da província no que se refere à quantidade de falantes.

A integração com outros grupos etnolinguísticos angolanos ocorreu durante a era colonial, em que muita gente da parte sul foi transportada compulsoriamente para esta província, além de esse processo ocorrer durante a guerra fratricida entre angolanos. É neste período em que se dá o hibridismo linguístico da população nessa província do país, em função daqueles que se dirigiam para as zonas não identificadas, dando lugar às interferências linguísticas entre pessoas:

\footnotetext{
Angola é o segundo maior país de língua oficial portuguesa. No entanto, o país encontra-se povoado com uma forte concentração nas cidades costeiras e tem como língua materna uma ou mais das 40 línguas existentes no país. As mais significativas são o umbundo (4.000.000), o quimbundo (3.000.000) e o kikongo (1.144.000 falantes). O português é falado como língua materna por apenas 57.600 falantes, majoritariamente, por habitantes dos centros urbanos do litoral, como elites e jovens. Dado o vasto território angolano, este é o segundo maior país de língua oficial portuguesa. No entanto, apresenta ainda como línguas maternas mais de quarenta línguas bantu (Bento, 2010, p.19).
}

Angola é considerada como o segundo maior condomínio da LP, fato que nos remete a refletir profundamente acerca da dose das políticas linguísticas que foram colocadas no sistema de educação em Angola durante a colonização. Esses 500 anos da colonização em Angola tiveram como resultados a destruição total do tecido sociolinguístico nacional, a banalização da nossa toponímia e a negação da nossa cultura em detrimento da europeia. Agora, volvidos 42 anos de independência nacional, o estado angolano, cônscio das suas responsabilidades, tem empreendido algumas ações em prol do resgate da nossa identidade. A título de exemplo, a comunicação social do programa Ngola yetu (nossa Angola), da Rádio nacional de Angola, é emitida de Luanda para todo o país em línguas nacionais. A televisão pública de Angola, por sua vez, incluiu recentemente no programa Bom dia Angola notícias em línguas nacionais.

Angola conta ainda com outros grupos etnolinguísticos não bantu - os khoisan - que constituem um grupo étnico minoritário em Angola (minoritário porque 
tem menos população em relação à tribo, representando menos de $10 \%$ da população de todo o país). Segundo a história, os khoisan são uma tribo que, desde os primeiros anos, habitou Angola, em especial, a Província do Kwando Kubango. As investigações não confirmaram até à data, donde e quando vieram. Sabe-se, apenas, que durante o processo de migração das comunidades, a tribo bantu quando veio do Centro da África já encontrou os Khoisan a viverem em Angola.

Os Khoisan são facilmente identificados, não apenas pelas suas características físicas da pele com tonalidade amarela, estatura baixa, cabelos encaracolados, olhos com pálpebras que cobrem o ângulo interno, mas, sobretudo pela sua forma de falar, pelos estalidos da língua que produzem na zona dental, labial e palatal. São os famosos cliques. Jaime (2014), na sua obra sobre os Khoisan e sua comunicação e processo de socialização (Província do Kuando Kubango), procurou saber como é que os khoisan aprenderam a falar português e sobre as línguas locais:

Quanto à aprendizagem da Língua Portuguesa, até à data, existe por parte dos khoisan pouco interesse na mesma. Os falantes de língua portuguesa são muito poucos, pois a falta de necessidade de saberem a língua conduz à ausência de interesse na sua aprendizagem desta tribo apenas dois elementos, professores do ensino primário na localidade de Mbundu (Jaime, 2014, p.57).

O grau de escolaridade dos San é bastante baixo. Isso se deve não só à vida nómada que levam, mas também à falta de escolas no seio das suas comunidades. $\mathrm{O}$ autor continua ainda:

\footnotetext{
O conflito armado que o pais viveu, especificamente, a Província do Kuando Kubango possibilitou os primeiros contactos e o convívio dos bantu com os Khoisan, motivado também pelas trocas comerciais entre ambos. Dai que muitos membros da tribo San começassem a adoptar alguns comportamentos dos bantu, por exemplo, a cozinharem os alimentos a assar a carne e a construírem cabanas para se proteger das chuvas e dos animais ferozes(...) No entanto, pode-se afirmar que o interesse dos Khoisan em aprenderem as línguas dos bantu sempre foi maior motivado pelas trocas comerciais do que o interesse dos bantu em aprenderem a língua dos khoisan (Jaime, 2014, p.56).
}

\section{Multilinguismo em Angola}

Em Angola, independentemente da dimensão geográfica e da densidade demográfica, a sua situação linguística e cultural decorre de fatores históricos e sociais. Assim, no país, coexistem várias línguas étnicas com a LP, além de línguas dos imigrantes no caso especifico dos congoleses do Congo Kinshasa e Brazaville que se instalaram no país antes e após a independência Nacional. Essa diversidade faz de Angola uma sociedade plurilíngue e pluricultural, resultado de convivências com várias etnias, várias línguas e várias culturas.

Nota-se que as línguas nacionais concorrem num mesmo espaço, como no caso específico do Município de Maquela do Zombo (um dos municípios do 
Uíge), com a LP, lingala, swahili, tchiluba e, em alguns casos, com a Língua Francesa. A primeira tentativa de inserção das línguas nacionais de origem bantu faladas em Angola no sistema educacional surgiu na década de 1980, concretamente em 1985, data em que estas são introduzidas no processo de alfabetização. Porém, apenas dois anos mais tarde, é publicada a Resolução n ${ }^{\circ}$ 3/87, de 23 de Maio, que aprova, a título experimental, os alfabetos das línguas kicongo, kimbundo, tchócue, umbundu, mbunda e oxicuanhama, bem como as respectivas regras de transcrição. Mas só em 2006 que foi implementado e generalizado, ainda que de uma maneira tímida e regional, o ensino de línguas angolanas em todos os subsistemas de ensino em Angola.

Segundo Mudiambo, (2014, p.79), “o Lingala é uma das línguas bantu, falado como idioma materno na região noroeste da República Democrática do Congo e uma grande parte da República do Congo Brazzaville. Além disso, serve como língua franca em toda extensão do território do primeiro país ..." No entanto, o lingala, em Angola não faz parte do conjunto das nossas línguas nacionais, porém, com o andar do tempo e a evolução das sociedades, tem vindo a ocupar um lugar de destaque. Depois da independência de Angola, em 1975, com a entrada no país de centenas de milhares de pessoas vindas do ex-Zaire, o lingala expandiu-se, tendo um estatuto próximo de Língua Nacional. Também hoje em Portugal e no Brasil, devido à já considerável imigração dos congoleses, não é raro ouvir-se conversações em Lingala. Falar do estatuto ou função social do lingala em Angola é debruçar sobre um fenômeno complexo, tendo em conta o seu nível de abrangência e o caráter contrastivo que essa língua apresenta nessa sociedade: é a língua mais usada na sociedade informal (famílias, mercados, campos de futebol). Também é considerada, por alguns estudiosos dos fenômenos da linguagem, como língua franca.

No contexto cultural, os povos de Angola enfrentam heranças da política colonial, na medida em que ainda se referem aos seus próprios valores para julgar os outros, o que conduziu à negação das diferenças culturais, em nome da superioridade da sociedade colonial. Esta atitude levou ao esvaziamento da qualidade cultural do povo angolano e, não só: levou também ao tratamento degradante dos nomes antroponímicos das línguas de Angola. Por isso, constata-se, hoje em Angola, a rejeição total e deturpação de nomes de origem bantu propostos pelos pais, para colocar nomes estrangeiros que não representam nada no nosso mosaico cultural. Essa rejeição pode ser entendida como resultado de um longo processo de assimilação importada pela administração colonial. Aliás nem todos os angolanos aceitavam estas políticas assimilacionistas, foi o caso da Rainha Nzinga Mbandi, no Reino do Ndongo que em fevereiro de 1929, tinha escrito uma carta, da qual extraímos algumas passagens: 
Ao vosso Governador, Sr. Fernão de Sousa. Ide dar lhe este meu recado. E dizei-lhe também que o nome de Ana de Sousa que o outro me quis oferecer não pegou. Não podia pegar. O mesmo sucede com as minhas irmãs, a Kambo não quer o nome de Bárbara e a Fuxi manda dizer que o seu nome é mesmo Fuxi. Que ide aplicando o nome de Engrácia as vossas filhas que is parindo vós outros. Mau grado os esforços todos meus para uma possível conciliação entre vós e nós, entre as nossas coisas e as vossas (Kukanda, 1988, p.56).

Hoje a juventude, refugiando-se na globalização, opta em atribuir aos seus filhos nomes de origem portuguesa, francesa, inglesa e espanhola e nem sempre os filhos que são portadores destes nomes sabem explicar o significado real destes nomes.

\section{Política e a planificação linguística em Angola}

Políticas linguísticas são decisões que se tomam para resolver problemas linguísticos, pelos órgãos de estado ou da comunidade, a fim de influenciar a implementação do uso ou não de uma língua dentro de um determinado espaço territorial. Segundo Calvet (2002, p. 145), define-se "política linguística [como] um conjunto de escolhas conscientes referentes às relações entre língua (s) e vida social, e planificação linguística [como] a implementação prática de uma política linguística, em suma, a passagem ao acto".

Para o autor, as políticas linguísticas podem ser elaboradas por grupos que desempenham papéis distintos na organização social, mas apenas o Estado tem o poder e os mecanismos para pôr em prática determinadas escolhas. Oliveira (2003) esclarece que a política linguística é o conjunto de decisões que um grupo de poder, sobretudo um Estado (mas também uma Igreja ou outros tipos de Instituições de poder menos totalizantes) toma sobre o lugar e a forma das línguas na sociedade (Oliveira, 2003; 2005).

A política linguística é uma disciplina emergente, sobretudo nas universidades africanas, mas ainda são poucos os estadistas africanos que têm uma visão em torno das ações que se devem empreender para aplicar uma política linguística em seus territórios. Este desconhecimento faz com que uma boa parte dos países africanos continue ainda a ser exoglóssico, isto é, promover mais a línguas dos ex- colonizadores em detrimentos das suas línguas locais ou nacionais. Os países africanos de expressão portuguesa, nomeadamente Angola, Cabo Verde, Guiné-bissau, São Tomé e príncipe e Moçambique, todos subscreveram nas suas constituições que a língua portuguesa é a única língua oficial, pese embora que Cabo verde já marca alguns passos titubeantes para a co-oficialização da língua crioula.

Em Angola, o processo de colonização pôs em contacto duas comunidades de origem diferentes: de um lado, uma comunidade portuguesa (colonizadora) 
e, de outro, uma comunidade linguisticamente heterogênea, tendo como meio de expressão línguas bantu e não bantu. A política linguística colonial tinha um único objetivo: dominar os povos africanos através da implementação do sistema colonial nas suas colônias. Esta política deu certo haja vista que todos os africanos "não assimilados" sofriam todo tipo de preconceitos e complexo de inferioridade. No entanto, essa segregação racial e linguística despertou "a consciência africana", que culminou na preparação e luta contra o colonialismo.

Assim, o Estado angolano impunha o uso obrigatório da LP em todos os planos: sociais, econômicos, político, jurídico, administrativo e comunicativo etc. Estas decisões tomadas pelos dirigentes do Movimento Popular de Libertação de Angola (MPLA) parecem ser a mais acertada na altura. Atendendo à diversidade linguística dos reinos que formaram a então República de Angola, por coexistir várias línguas, seria um tanto conflituoso se se dotasse uma língua local como língua oficial na procura de uma Angola indivisível para a unidade de todos os angolanos, sem que se pusesse em questão as convicções étnicas, políticas, religiosas. Isto justifica que, ao tomar estas decisões, os políticos não queriam beneficiar ou favorecer alguns e colocarem dificuldades a outros. Isto viria a ser outra guerra linguística, devido à aproximação entre o Estado e as populações que não falassem a língua adotada e comprometeria a unidade nacional.

Mas, nesta perspectiva, consideramos uma falha o fato de não se colocar no plano de ensino, de maneira faseada, uma das línguas nacionais ou regionais com a obrigatoriedade de ser uma disciplina de ensino a todos os subsistemas de educação, porque a valorização e a promoção destas línguas devem encontrar o ensino como o espaço para atingir todas as faixas etárias dos falantes. Nesse sentido, o desenvolvimento das línguas maternas ficou restrito à transmissão oral de geração adulta para a geração jovem. Face a esta implicatura, seria difícil Angola adotar uma língua local na sua política como língua oficial, pois a jovem nação precisava de uma abertura ao nível do contexto das nações. Para essa abertura, o acesso seria facilitado se feito em Língua Portuguesa, por ser um idioma reconhecido no contexto internacional. Assim, a adoção da LP facilitou as relações diplomáticas e econômicas com outros países.

Para além do português, existem mais de vinte línguas angolanas de origem africana, com 90 (noventa) a 100 (cem) variantes umbundu, kimbundu, kikongo, tchokwé, fiote/ibinda, nganguela, nyaneca-humbi e kwanyama. Nenhuma destas línguas tem a categoria de oficialidade (status), ficando apenas no plano de relações mais próximas, em nível local. Há uma experiência piloto da inserção destas línguas no Sistema de Ensino, que ainda está na sua fase inicial. Foram aprovados, a título experimental, pela Resolução no 3/78, de 23 de maio de 1987, do Conselho 
de Ministros, os alfabetos das línguas kikongo, kimbundu, umbundu, cokwe, oxikwanyama e mbunda e suas respectivas regras de transcrição (Gomes, 2014).

Com a aprovação dos alfabetos e das normas de transcrição das seis línguas de Angola, começava um processo de planificação linguística, abrindo, assim, a possibilidade de políticas linguísticas regionais, já que as línguas, cujos alfabetos foram aprovados, eram de circunscrições regionais. As línguas com alfabetos aprovados pelo Estado estão em vias de serem inseridas no Sistema de Ensino, mas, esta inserção precisa de um instrumento legal que possa conferir às referidas línguas um posicionamento social, ou seja, a definição do estatuto dessas línguas. Ao serem inseridas, serão avaliadas em que categoria? Línguas nacionais, línguas co-oficiais? Dentro desta planificação, falta ainda um equipamento, que é o repertório lexical (Gomes, 2014, p. 60). Por Decreto $\mathrm{n}^{\circ}$ 40/85, de 18 de novembro de 1985 do Conselho de Defesa e Segurança, foi criado o Instituto de Línguas Nacionais, com os seguintes objetivos:

\footnotetext{
a) Estudar todas as Línguas Nacionais, iniciando pelas que têm maior representatividade numérica; b) Estimular a preservação das Línguas Nacionais, a sua promoção e consequente valorização, no quadro da sua competência; c) Contribuir para o esclarecimento da opinião pública quanto à importância e utilidade da investigação no domínio que lhe é próprio; d) Dinamizar por meios apropriados, a divulgação dos conhecimentos científicos, adquiridos pela sua atividade de investigação, tanto no País, como fora dele, quando for de interesse da República Popular de Angola; e) Criar a infraestrutura necessária, em colaboração com outros organismo, dentro e fora do país, a fim de proceder, a longo prazo, as investigações que contribuirão para o conhecimento da realidade linguística na República Popular de Angola; f) Colaborar com os organismos afins, cujas atividades interferem no domínio que lhe é específico; g) Cooperar, quando para tal autorizado, com os organismos estrangeiros e organizações internacionais, na permuta de informações e na realização de estudos e trabalhos científicos do seu interesse. (Estatuto Orgânico do Instituto de Línguas Nacionais, capítulo I, artigo 3).
}

Um passo decisivo foi dado pelo I Congresso do MPLA, em 1977, ao decidir incrementar o estudo das nossas línguas Nacionais com vista à sua aplicação na alfabetização e no Ensino. A tarefa de estudar cientificamente as Línguas Nacionais, que é uma atividade complexa e difícil, levou o INL, a partir de 1978, a desenvolver o Projeto de ANG 77/009 de desenvolvimento das Línguas Nacionais em todo território, assinando entre Angola e a UNESCO um convênio de apoio à assistência desta organização internacional. E como fruto desta cooperação, o INL publicou em 1980 e 1982 os livros história sobre a criação dos alfabetos em Línguas Nacionais que apresenta o kimbundu, Cokwe, Umbundu, Mbunda e Kwanyama (Kukanda, 1988).

\section{Proposta para uma educação bilíngue em Angola}

Em setembro de 2006, o $3^{\circ}$ Simpósio sobre Cultura Nacional, que teve lugar em Luanda, relançou a questão das Línguas Nacionais. É fato sabido que 
muitas crianças angolanas chegam à escola conhecendo e utilizando somente a sua língua materna, no caso uma língua angolana de origem africana na modalidade oral, e geralmente uma variedade linguística adquirida no contexto familiar. Surgida na década de 60, nos Estados Unidos, como uma resposta política aos problemas educacionais das crianças que chegavam à escola falando uma língua diferente daquela que era usada como meio de instrução, a educação bilíngue assumiu, a princípio, características de ensino compensatório. Essas crianças tinham uma proficiência limitada no inglês e, quando comparadas com as crianças anglófonas, apresentavam baixo rendimento e alto índice de abandono escolar. Para sanar esses problemas, foram criados programas especiais, cujo objetivo inicial era de desenvolver a habilidade linguística dessas crianças no inglês, a fim de que rapidamente elas pudessem ser colocadas nos programas regulares de ensino.

Considerando que muitas crianças entram na escola sem o conhecimento de língua portuguesa, a educação bilíngue seria uma solução para elas e para tantas outras anônimas que estão no sistema de ensino em Angola (Mello, 2010). Seria um processo de ensino que começaria com a língua materna, no caso a língua angolana de origem bantu ou khoisan dos alunos, como meio de ensino. Isto é, o ensino primário começaria com uma língua materna, com uma transição gradual para a língua segunda no caso a LP no $1^{\circ}$ Ciclo.

As instruções na sala de aula poderiam ser dadas em ambas as línguas de uma maneira simultânea e, nas classes subsequentes, as instruções poderiam ser dadas primeiro na Língua Materna, em que o aluno é ensinado, até ser capaz de usar a língua portuguesa como um meio de aprendizagem. O que nos motiva a propor o ensino bilíngue em Angola, é que o ensino em línguas angolanas de origem africana - Língua Materna (LM) da maioria da população rural - reduziria a ineficácia do sistema educativo, que é realizado em LP, segunda língua (L2), falada por uma minoria das populações das zonas rurais. Os discursos oficiais, por exemplo, reconhecem a importância das línguas nacionais, incentivam a sua implementação no sistema de ensino, contudo a prática tem mostrado que entre a intenção e o fazer há uma distância considerável.

Sabe-se que, a LP continua ainda até a data presente como a língua de Unidade Nacional em Angola, de forma que qualquer angolano que quiser participar ativamente no processo de reconstrução do país precisaria aprender a falar a LP. Os resultados que se esperam do ensino bilíngue são vários, dentre os quais citaremos apenas alguns:

a) Possibilidade de manutenção das línguas angolanas de origem bantu; 
b) Contribuir para o desenvolvimento intelectual das crianças com dificuldades em Língua Portuguesa;

c) Contribuir para definição de Políticas Linguísticas em Angola;

d) Otimizar uma educação multicultural, integrando no currículo conteúdos sobre a cultura dos alunos e da sua comunidade;

e) Ajudar os alunos a conservar os seus valores, usos e costumes étnicos que lhe são transmitidos desde a sua tenra idade na sua língua materna.

Verificamos que é fundamental um ensino bilíngue no ensino primário em Angola, sobretudo nas zonas rurais que propicie o conhecimento da estrutura ortográfica e gramatical da língua materna do aluno, para ser possível um processo de ensino-aprendizagem eficaz, que atenda as reais necessidades da comunidade, uma vez que o conhecimento só poderá ser possível após a aquisição da leitura e escrita pelos alunos, assim como acontece no processo de construção do conhecimento da estrutura da língua portuguesa.

\section{Conclusão}

Retomando a questão inicial que questionava se a atual reforma educativa conseguiu resolver a problemática do ensino de Línguas Nacionais em Angola, temos a responder que a reforma educativa, aprovada em 2001 pela Assembleia Nacional de Angola, procurou consolidar a concretização dos princípios da integridade, laicidade, democratização, gratuidade e obrigatoriedade do anterior sistema educativo. Esta reforma representa uma estratégia para melhorar a qualidade da educação e do ensino e responder aos desafios do desenvolvimento do país. Contudo, a atual reforma não conseguiu resolver a problemática de ensino de línguas nacionais no ensino primário, pois continuamos a registrar situações de alunos sem conhecimento de Língua Portuguesa nas salas de aulas, sobretudo nas zonas de fronteira, onde encontramos alunos que só falam o português quando estão na Escola e com o professor. Isso faz com que sintam dificuldades enormes na compreensão das aulas ministradas em LP.

Com a análise dos dados teóricos assim como dos empíricos, chegou-se a conclusão de que o uso e a prática das línguas nacionais em Angola é fundamental para uma redefinição das políticas linguísticas no sistema Nacional de Educação, apesar de o artigo 19 da Lei constitucional defender que "A língua oficial da República de Angola é o português." e "O Estado valoriza e promove o estudo, o ensino e a utilização das demais línguas de Angola, bem como das principais línguas de comunicação internacional" (Angola, 2010). Na prática, ainda existe um longo caminho a percorrer. A título de exemplo, as duas operadoras de telefonia móvel de Angola (UNITEL e a MOVICEL) com cobertura até em algumas zonas 
rurais onde a presença de Língua Portuguesa não é visível, mantêm as funções dos telefones todas em LP e Línguas estrangeiras. Assim sendo, o país deveria co-oficializar algumas línguas angolanas com maior número de falantes nomeadamente: Umbundo, Kibundu, Kikongo, Tchokwe quatro línguas e as outras teriam um valor concorrente como, por exemplo, o Nhaneka-Humbi, Kuanhama, Nganguela, etc.

A inexistência de uma ortografia normalizada para as línguas bantu de origem angolana tem criado vários problemas. Nesse sentido, muitos compatriotas angolanos escrevem: Kuando Kubango outros Cuando Cubango, Kikoongo, Kikongo e Quicongo, Cuanza sul ou KwanzaSsul, Nzinga Mbandi, Jinga Bandi, Njinga. No caso de Uíge, alguns escrevem Uije, outros Uiji e outros ainda, WIZI. Se África e, em particular Angola, deseja preparar bem os seus cidadãos para os desafios e realidades do século XXI, ela deve levar em conta a diversidade cultural e linguística como fenômenos importante e normal em qualquer parte do mundo. Em termos de orientações curriculares, devera implementar o mais rápido possível o ensino bilíngue nas zonas rurais no ensino primário. Neste contexto, a Língua Portuguesa seria uma disciplina e não o único meio de transmissão de conhecimentos.

\section{Referências}

Angola. Constituição da República de Angola. Luanda: Imprensa Nacional, 2010.

Angola. Decreto $n^{\circ} 40$ de 18 de novembro de 1985. Luanda: Imprensa Nacional, 1985.

Angola. Lei 13 do sistema de bases de educação de Angola. Luanda: Assembleia Nacional, 2001.

Angola. Resolução n³ de 23 de maio de 1987. Disponível em: <http://www.axl.cefan.ulaval. ca/afrique/Angola-loi-1987-3.htm>. Acesso em: 22 jun.2017.

Bento, Cristina Teresa J. S. Francisco. Contributos para uma caracterização linguística do luandense. 2010. 97p. (Dissertação). Universidade de Aveiro: Aveiro, 2010.

Calvet, Louis Jean. As políticas linguísticas. São Paulo: Parábola, 2002.

Fundação António Agostinho Neto. 2016. Disponível em: <http://www.agostinhoneto.org/>. Acesso em: 22 jun.2017.

Gomes, Silvestre Filipe. Relações entre língua oficial e línguas locais na escola: como as crianças de aldeias de Cabinda/Angola aprendem o português e em português. 2014, 150p. (Dissertação de mestrado). Faculdade de Educação da UFMG, Belo Horizonte, 2014.

Instituto Nacional de Estatística. Luanda: INE, 2016. Disponível em: $<$ http://www.ine.gov.ao/ xportal/xmain?xpid=ine>. Acesso em: 22 jun.2017.

Jacinto, Félix. Estudo comparativo da variedade do português falado nos municípios do Uíge e Dange-Quitexe: principais interferências. 2016, 64p. (Monografia). Instituto Superior de Ciências da Eduacação do Uíge, Uige, 2016. 
Jaime, José. Os khoisan, Luanda: Rubricat, 2014.

Kukanda, Vatomene. Introdução à Sociolinguistica. Centro de Documentação e Informação. Lubango: ISCED, 1988.

Liberato, Ermelinda, Avanços e retrocessos da educação em Angola. Revista Brasileira de Educação. v.19, nº59. Rio de Janeiro. p. 42-74, oct./dec. 2014.

Mello, Heloisa, Educação bilíngue: uma breve discussão. Horizontes de Linguística Aplicada, v. 9, n.1, p. 118-140, 2010.

Mudiambo, Quibongue. Estudos linguísticos sobre a lexicologia e a lexicografia de aprendizagem aplicada ao ensino da língua portuguesa. Lisboa: Colibri, 2014.

Oliveira, Gilvan Müller de (Org.). Declaração Universal dos Direitos Lingüisticos: novas perspectivas em política lingüística. Campinas (SP): Mercado de Letras, Associação de Leitura do Brasil (ALB); Florianópolis: IPOL, 2003.

Oliveira, Gilvan Müller de. Política lingüística na e para além da educação formal. Estudos lingüisticos. XXXIV, p. 87-94, 2005. Disponível em: <http://etnolinguistica.wdfiles.com/local--files/ journal:estudos/oliveira_2005_politica.pdf $>$. Acesso em: 22 jun.2017.

Quiala, Miguel, Longoka kikongo. Luanda: Mayamba, 2013.

Quivuna, Manuel. Lexicologia aplicada ao ensino de léxico em português língua não materna. Lisboa: Colibri, 2014.

Rodrigues, Marília dos Prazeres. A língua portuguesa como língua segunda na Província do Huambo. 2012. 264p. (Tese). Universidade Nova de Lisboa: Lisboa, 2012.

Santos, Eduardo, José dos. Discurso de abertura do $3^{\circ}$ simpósio sobre a cultura nacional. Luanda, 11 de setembro de 2006. 